\title{
El paso de la Ley de Sucesión por las Cortes Españolas: ¿Hacia la continuidad del Régimen?
}

\author{
Luis Miguel FernándeZ
}

"Con una Corona y un Trono, y aún sin Rey, muchas veces pueden regirse los pueblos».

J. Calvo Sotelo: El Estado que queremos.

El 28 de marzo del año 1947, el Gobierno acordó el envío a las Cortes del proyecto de Ley de Sucesión a la Jefatura del Estado. Su proceso de redacción fue breve, pero en ella intervinieron diversas personas, fundamentalmente algunos ministros y el presidente de las Cortes que, a su vez, era presidente de la Comisión especial encargada de su estudio. Por ello, nos es lícito afirmar que «en Estoril se ignoraba todo sobre la disposición e incluso el hecho mismo de que estaba siendo preparada»'. Pero el proyecto no sólo se limitaba a reglamentar la sucesión en la Jefatura del Estado, sino que además, englobaba una serie de ideas que tenían tanta trascendencia como la sucesión. Así, se constituía a España en Reino, se creaba el Consejo de Regencia y el Consejo del Reino, se atribuía la Jefatura del Estado al general Franco, creaba la categoría de Leyes Fundamentales... Se trataba, pues, de un complejo de intenciones que hicieron afirmar al conde de Barcelona que "...lo que ahora se pretende es pura y simplemente convertir en vitalicia esa dictadura personal, convalidar unos títulos según parece hasta ahora precarios, y disfrazar con el manto glorioso de la Monarquía un régimen de puro arbitrio gubernativo, la necesidad del cual ya hace mucho tiempo que no existe ${ }^{2}$, no siéndonos extraña tal

1 J. TUSELL: Franco y los católicos. Política interior española entre 1945 y 1957. Alianza Universidad. Madrid, 1984, págs. 158-160.

${ }^{2}$ El manifiesto de don Juan sobre la Ley de Sucesión en José María GiL Robles: La Monarquía por la que yo luché. (1941-1954). Taurus. Madrid, 1976, págs. 388-390. 
afirmación por cuanto el proyecto encubría un atinado propósito: instaurar en un futuro lejano -a la vez que deseable- una Monarquía al estilo tradicional, relegando los derechos que al Trono mantenía don Juan.

Tras ser recibido el Proyecto por el presidente de las Cortes, éste ordenó inmediatamente su publicación en el Boletín Oficial de las Cortes, apareciendo así el día 11 de abril de $1947^{3}$. A continuación se ordenó su paso a la Comisión correspondiente, que en este caso fue una Comisión Especial compuesta por treinta y dos miembros. Nombrada la Ponencia que había de encargarse del estudio del Proyecto, los Procuradores, en un plazo de quince días a contar desde la fecha de publicación del Proyecto en el Boletín Oficial de las Cortes podrían enviar por escrito a la Ponencia las enmiendas que estimasen pertinente formular a la totalidad o al articulado del proyecto con las razones y fundamentos que lo aconseja$\operatorname{sen}^{4}$. El 26 de mayo, la Ponencia, conforme al artículo 36 del Reglamento, emitió un informe, que José Luis Arrese no firmó, siendo objeto de deliberaciones en el Pleno de la Comisión durante los días 30 y 31 de mayo. El dictamen de la Comisión se aprobó para su posterior aprobación de las Cortes, el día 31, siendo defendido por el presidente de la Comisión, don Esteban Bilbao, el 7 de junio del mismo año. El proceso culminó con su aprobación el día 6 de julio, convirtiéndose con la sanción del Jefe del Estado en la Ley de 26 de julio de $1947^{5}$.

A partir del estudio de las enmiendas presentadas al proyecto y de las deliberaciones que se producen en el Pleno de la Comisión Especial, juntamente con el análisis del paso por el Boletín Oficial de las Cortes del mismo, esperamos dar una imagen lo más certera posible de la «mentalidad» que inspira la Lèy. En efecto, es nuestra intención descubrir el espíritu del proyecto como también discernir la intención de las enmiendas presentadas, puesto que, a pesar de que el Proyecto llega a las Cortes con pocas posibilidades de discusión debido a la naturaleza del régimen, la configuración de las propias Cortes, la lealtad al principio inspirador del Caudillo, etc..., éste es foco de discusiones y desacuerdos, aunque mediatizadas a priori por una voluntad incondicional al Caudillo, que de hecho se refleja en el artículo $2^{\circ}$ que estatuye una afirmación rotunda, que «en contadas palabras expresa con una deuda de justicia el eco de la clamorosa demanda nacional: "La Jefatura del Estado corresponde al Caudillo de

\footnotetext{
${ }^{3}$ Bol. Oficial de las Cortes, núm. 194, págs. 3911-13.

${ }^{4}$ Reglamento Provisional de las Cortes. Textos refundidos del 5 de enero de 1943 y 17 de julio de 1946.

${ }^{5}$ Aprobación en el Pleno en $B O C$ de 7 de junio de 1947, núm. 204, págs. 4018-4025.
} 
España y de la Cruzada, Generalísimo de los Ejércitos, D. Francisco Franco Bahamonde" 6 .

Varias enmiendas merecen nuestra atención en este punto. Así, Lorenzo de Cura y Lope fundamentaba su enmienda en que «no se puede reconocer ningún derecho a nadie; a unos por abandono de ellos y a otros por no poder ejercerlos y, desde luego, todos lo han perdido"' ${ }^{7}$. Se trataba, pues, de legitimar la situación de Franco puesto que él había sido el que "con los buenos españoles recuperó la Nación" ", pudiendo "libremente instaurar la Monarquía en la persona que más garantías ofrezca para bien de todos" $"$. Nada había que decir relativamente a que la Jefatura del Estado recayese en el Generalísimo, «teniendo en cuenta que él supo ganar tan alta jerarquía», sentenciaba Emilio Laguna, puesto que «si los hijos debemos a nuestros padres la vida y por ello les veneramos, respetamos, admiramos y queremos, también los españoles honrados debemos la vida a nuestro Generalísimo, que en la zona nacional nos liberó...» En este punto consideramos paradigmático transcribir el siguiente párrafo de la enmienda de Luis Zabala Alonso, quien afirma:

«... no debemos buscar la solución en una Monarquía, que sería retrotraernos a los tiempos de la carreta cuando hoy se da la vuelta al mundo en 78 horas, cuando el pensamiento de hoy hace mucho que ha dejado de ser europeo para se americanista y dentro de la órbita del dólar y el peso, busca la unión espiritual con nuestros hermanos de raza... y máxime cuando el pueblo que tiene memoria, que se sabe soberano... sólo admite que el único que le gobierne sea el victorioso Caudillo al que quiere entrañablemente...; pero de esto a endosarle de nuevo un soberano de apellidos extranjeros aún nacido en España y con más o menos derecho a la Corona, va un abismo... El dilema es renovarse o morir, a las arcaicas formas de Estado ha surgido en los tiempos modernos económico-sociales, una nueva que es el Movimiento Nacional-sindicalista...; el pueblo liso y llano también tiene derecho a ser atendido, oido y escuchado, haciéndose a la idea de que existe un nuevo concepto que pide paso, el Franquismo, en cualquier forma de Estado o de gobierno" ${ }^{10}$.

6 BOC. pág. 4025.

7 Enmienda núm. 3.

8 Enmienda núm. 3.

9 Enmienda núm. 8.

10 Enmienda núm. 17. Digamos de paso que de las diecinueve propuestas de modificación presentadas por los Procuradores, sólo cinco merecen «reglamentariamente» la consideración de enmiendas. A juicio de la Ponencia, las catorce restantes son «en su mayoría beneméritos e interesantes trabajos que por no reunir el número de firmas... no es posible analizarlas como si de aquéllas se tratase». 
Vemos clara la intencionalidad política de la enmienda. No obstante, la enmienda fue rechazada por la ponencia «por alterar las bases esenciales del Proyecto y tratarse de una apreciación unipersonal del procurador”.

La misma tónica laudatoria del Caudillo se observa de la lectura de las actas taquigráficas de las sesiones de la Comisión Especial. Así, Manuel Valdés aclaraba que «nuestra enmienda en modo alguno significa cortapisa o reducción a lo que históricamente, por la victoria de las armas nacionales, corresponde de modo absoluto y total a la voluntad exclusiva del Caudillo", "persuadidos de que ha sido la salvación de España», además de «servir de manera fervorosa y sin reservas a esta etapa gloriosa del Caudillo, pidiendo a Dios sea cumplida en toda su amplitud para bien de España y felicidad de los españoles»...«¿Qué mayor legitimidad que la emanada de la propia voluntad heroica de los españoles? Y así como digo la legitimidad reside en el propio ser nacional, ¿a quién ha de corresponder el pleno título de legitimidad sino al que llevó a cabo las decisiones históricas trascendentales del presente momento?" ${ }^{11}$. Buena prueba de ello es que dieciséis cuartillas taquigráficas se dedican integramente a perfilar los títulos de Franco, que al fin aparecen plasmados en el anteriormente referido artículo $2^{\text {o12 }}$.

Por ello, según el presidente de las Cortes, Esteban Bilbao, convenía "apreciar el verdadero sentido de esta ley", por cuanto "no se trata -entendámoslo bien- de la inminencia de un traspaso" y "mucho menos del ensayo de una transacción vergonzante y temerosa, sino de la afirmación previsora, propia de los regímenes fuertes", para concluir tajantemente: «el trámite, si para una lejana sucesión» ${ }^{13}$.

Una visión sintética de las precedentes líneas puede resumirse en una frase de Herrera, quien aseguraba no ver «posible otro gobierno en España que el gobierno de Franco. El que le sustituya ha de ser traído por él». Herrera, por tanto, partía de la constatación del peso político del franquismo ante lo que declaraba como irremediable que la evolución hacia la Monarquía no tenía que enfrentarse en el régimen, sino hacerse a través de él ${ }^{14}$.

A’sí pues, Franco ostentaba en su persona tres dignidades que le catapultaban como supremo rector de la vida española: Caudillo, Generalísi-

11 Actas Taquigráficas del día 30 de mayo de 1947, $1^{\text {er }}$ turno, cuartillas 2 y 3.

12. Actas Taquigráficas del día 30 de mayo de $1947,2^{\circ}$ turno, cc. 33 a 49.

13 BOC, pág. 4019.

14 Javier TUSELL, op. cit., págs. 75-76. 
mo de los Ejércitos y Jefe del Estado. Más, esta última dignidad no parecía entrar en contradicción con el artículo $1^{\circ}$ de la Ley por el que «España, como unidad política, es un estado católico, social y representativo, que, de acuerdo con su tradición, se declara constituido en Reino". Efectivamente, la potencialización del Caudillaje descarta temporalmente la restauración monárquica, puesto que a partir de la Ley de Sucesión se pasa a defender la Monarquía como sustitución duracional, es decir, en palabras de Pemartín, como "continuidad histórica de la obra del Caudillo". Ciertamente, el Caudillo no puede ser un poder interino "porque es el poder total que hace la Historia ${ }^{15}$. En otras palabras, la primera piedra debía ser la construcción del Nuevo Estado, y una vez dado al Estado cimientos sólidos que entroncasen con la tradición y la continuidad de mando, entonces sería la hora de levantar el Trono.

En este contexto, ¿cuál era la formulación Monárquica más conveniente? Según Tomás Villarroya ${ }^{16}$ en el pensamiento de Franco la nueva Monarquía debía reunir dos notas imprescindibles: la eliminación de todo parecido con la que habia caído el 14 de abril y el retorno a una Monarquía tradicional. Efectivamente, la Monarquía tradicional representa, junto con el catolicismo, el eje fundamental de la concepción monárquica franquista, de tal modo que alejarse de la Monarquía tradicional sería alejarse de la esencia española. Ello daba lugar a la mitificación de la forma política monárquica que tuvo vigencia en la época del nacimiento del Estado Moderno español -con los Reyes Católicos- y en su período imperial posterior. Esta concepción encierra dos ideas claves: la unidad política nacional y la unidad religiosa. Pero, no nos debe extrañar esta concepción por cuanto en estos años los consejeros de don Juan invocaban también el nombre y la doctrina de la Monarquia Tradicional. Así, en las Bases institucionales de la Monarquia -conocidas como las Bases de Estoril- de 28 de febrero de 1946, se reivindican como postulados esenciales en los que descansará la vida política española y que no podrán ser objeto de discusión ni revisión, la religión católica y la unidad sagrada de la Patria, si bien se incluia la Monarquía representativa. Además se fijaba la religión católica como la religión del Estado, el rey ejercería sus prerrogativas asistido por un Consejo del Reino, etc. ${ }^{17}$.

Se trataba, pues, de instituir un Estado representativo, apoyándose cuanto fuera posible en las instituciones tradicionales españolas, huyendo

15 J. Pemartin,: «¿Qué es lo nuevo?, en Raúl Morodo, Los origenes ideológicos del Franquismo. Acción Española. Alianza Universidad, Madrid, 1985, pág. 185.

16 Tomás VILLARRoYa.

17 "Las Bases de Estoril», en GIL RoBLes, op. cit., págs. 383-385. 
de la representación individualista de los partidos políticos y de la ilimitada libertad de prensa y de expresión. Los instrumentos para cumplir esta tarea serían una "Monarquía recibida de la Tradición, que se hace consustancial con la nacionalidad española»; "un órgano representativo de los intereses existentes en la sociedad española», que podría ser la organización sindical y una "cámara que represente los intereses morales de la sociedad española» ${ }^{18}$.

Esta Monarquía tradicional, obviamente, era incongruente con la Monarquía liberal y parlamentaria, a la que se atribuía el desgobierno de España en el siglo pasado y en el presente. Para evitar el posible desliz hacia esta formulación monárquica, la Ley de Sucesión trataba de condicionar el ejércicio en la Jefatura del Estado, por cuanto el artículo $9^{\circ}$ afirmaba que «para ejercer la Jefatura del Estado como rey o regente, se requerirá ser varón y español, haber cumplido la edad de treinta años, profesar la Religión Católica, poseer las cualidades necesarias para el desempeño de su alta misión y jurar las Leyes Fundamentales, así como la lealtad a los principios que informan el Movimiento Nacional», porque, como expresaba el Presidente de las Cortes ante el Pleno el 7 de junio de 1947, resucitar "los sistemas y las instituciones que nos llevaron a tan dolorosos desastres sería mucho peor que un delito de lesa patria, porque equivaldría al suicidio de un pueblo a la hora misma en que la Providencia le muestra los caminos de su resurrección tras el calvario de su inmensa tragedia ${ }^{19}$.

Varias enmiendas pueden resumir esta inquietud. Así, Alberto García Ortiz manifestaba que para ejercer la Jefatura del Estado «se requerirá... tener capacidad y don de mando y haber prestado relevantes servicios a la Patria ${ }^{20}$. Por su parte, Manuel Alvarez Valdés reconocía que «las personas que sean incapaces para gobernar o hayan hecho cosa por la que se merezcan perder el derecho a la Corona, serán excluidas de la sucesión por medio de una Leys ${ }^{21}$. La enmienda de José del Río requeriría que se suprimiese la frase "con mejor derecho», "ampliándose y facilitándose de este modo las facultades del Consejo, el Gobierno y las Cortes para elegir libremente la persona de sangre real que mejor pueda servir a los destinos de la Patria....”22.

\footnotetext{
18 J. TuselL, op. cit. pág. 85.

BOC, pág. 4019.

Enmienda núm. 11.

21 Enmienda núm. 4.

22 Enmienda núm. 7.
} 
Las referencias a don Juan eran claras, tratando deliberadamente de excluirlo de la sucesión al Trono. Esto no es extraño en un momento en que las relaciones entre el pretendiente y don Juan pasaban por la fase de mayor distanciamiento ${ }^{23}$.

A pesar de los encomios y elogios hacia la figura de Franco y el deseo de la Ponencia y los Procuradores de perpetuar, sin ningún tipo de matización, a éste en la más alta magistratura de modo vitalicio, surgió, no obstante, una enmienda reveladora y demasiado arriesgada en este ambiente de sumisión al espíritu del Proyecto, aun cuando era clara la intención de relegar a don Juan de todo posible derecho a suceder en la Corona. Esta enmienda fue la apreciación del procurador José Luis de Goyoaga y Escario, designado en elección por la Excma. Diputación Provincial de Vizcaya, para quien el artículo $1^{\circ}$ debía quedar redactado de la siguiente forma: «España como unidad política es un Estado Católico y Social que, de acuerdo con su tradición, se constituye de nuevo en Reino. Con arreglo a los principios y leyes hereditarias que en España rigen en materia de sucesión a la Corona, corresponde la Jefatura del Estado a DON JUAN DE BORBON Y BATTENBER". Tan manifiesta era su intención que, proponía como artículo $2^{\circ}$ el siguiente: «Mientras se efectúe la transmisión de poderes continuará desempeñando la Jefatura del Estado el Caudillo de la Cruzada y Generalísimo de los Ejércitos, don Francisco Franco Bahamonde». De esta.manera, las Cortes serian las encargadas de fijar el plazo dentro de la Ley en el cual se efectuaría la transmisión de poderes «con las fórmulas y solemnidades que las mismas señalen» ${ }^{24}$. La Ponencia rechazó la enmienda «por implicar una honda transformación del Proyecto, que lo altera en sus bases esenciales" y por «limitarse la propuesta a una apreciación unipersonal del firmante». Llama, naturalmente, nuestra atención tal enmienda por cuanto como afirmaba el Presidente de la Comisión había que tener presente» la delicadeza de nuestra misión. Este es un proyecto de Ley que el Caudillo ha proclamado por la radio ante toda la opinión nacional y poner mano en él es realmente cosa delicada ${ }^{25}$. Mas, esta enmienda de Goyoaga no dejaba de ser una pequeña gota en el inmenso océano de alabanzas al statu quo, aunque como veremos más adelante, desde otro ala del franquismo -la Falange- también

\footnotetext{
23 J. TUSELL, op. cit, pág. 142.

${ }^{24}$ Enmienda núm. 10.

25 Actas Taquigráficas de la Sesión de la Comisión Especial del dia 30 de mayo de 1947, $3^{\text {er }}$ turno, c. 7. Tanto las actas, como las enmiendas, el informe de la Ponencia y el Dictamen de la Comisión, y que se encuentran en el Expediente de la Ley de Sucesión en la Jefatura del Estado, legajo 3.336, núm. 3, han sido puestos a nuestra disposición por parte de los empleados del Archivo del Congreso de Diputados.
} 
surgió oposición al espíritu que informaba el Proyecto de Ley de Sucesión a la Jefatura del Estado.

Pero, donde más nos hemos de detener es en el punto nodal del Proyecto: la sucesión, porque fue en esta cuestión donde hubo el mayor número de enmiendas que pedían la aclaración de tamaño confusionismo. Al amparo del artículo $7^{\circ}$, «en cualquier momento el Jefe del Estado podrá proponer a las Cortes la designación de la persona que, reuniendo las condiciones que la Ley establece, estime deba ser llamado en su día a sucederle», mientras que de conformidad con el artículo $3^{\circ}$ "en caso de muerte o incapacidad será llamado a suceder en la Jefatura del Estado la persona de sangre real con mejor derecho que reúna las condiciones que esta Ley establece..." Así pues, Franco alcanzaba una absoluta y soberana libertad a la hora de designar a su sucesor, mientras que la propuesta de candidato hecha por el Consejo del Reino y el Gobierno debía circunscribirse a la persona de sangre real con mejor derecho.

Ante tal confusionismo, la enmienda de Serrano Súñer advertía la complejidad de fondo y el escaso rigor del texto propuesto. Por lo tanto -en la intención de Serrano Súñer- "sería prudente»-respecto al artículo $3^{\circ}$ - limitarlo a las normas que regulen el restablecimiento de la Monarquía cuando el Caudillaje haya terminado su misión; esto es, normas para un solo caso, dejando cauce abierto para una segunda ley que regule, según la tradición y en una constitución que pueda someterse a plebiscito, el derecho de sucesión. El enmendante también se refería a la intervención de las Cortes, que serian las responsables de aceptar la propuesta del Consejo del Reino y del Gobierno. Esta intervención -continuaba Serrano Súñer- «en los términos del proyecto de Ley, significa un título de adquisición del derecho, lo que implica una contradicción con el principio de que alli se parte, de proponer al que tenga mejor derecho ${ }^{26}$. En efecto, la tenencia de ese derecho -ya propuesta- hacía superflua la aceptación de las Cortes, si es positiva, o da ocasión a éstas de conculcar ese derecho, si la aceptación no se produce. En último término, Serrano evidenciaba en el proyecto la falta de determinación del orden de relación para calificar ese mejor derecho en términos de primogenitura, prioridad de línea, etc. Por último, rechazaba el artículo $7^{\circ}$ del proyecto por cuando «no se expresa claramente si es un precepto que se agotaría con su cumplimiento inmediato por una sola vez. Si es de aplicación ulterior y sucesiva... debe pensarse en la gravedad del evento de que las Cortes, en discrepancia y aun en pugna abierta y manifiesta con el Jefe del Estado, rechacen la

${ }^{26}$ Enmienda núm. 9. 
candidatura del sucesor propuesta por él, desautorizando su criterio en asunto tan trascendental.

Por todo ello, Serrano Súñer refundía los artículos $3^{\circ}$ y $7^{\circ}$ del proyecto en uno solo que tendría la siguiente redacción: «El actual Jefe del Estado, asesorado por el Consejo del Reino, hará la proclamación de la persona de sangre real en quien, conforme a las normas de sucesión de la Corona, recaen los derechos de la Monarquía española. En defecto de esta designación, fallecido o incapacitado el actual Jefe del Estado, compete al Consejo del Reino el ejercicio de dicha aclaración ${ }^{27}$.

En una misma línea podríamos situar la enmienda de Francisco Uranga Galiano, para el que los artículos $3^{\circ}, 4^{\circ}$ y $7^{\circ}$ debían refundirse en uno solo que rezase así: «En el momento en que el Jefe del Estado lo determine o en caso de muerte o incapacidad será llamado al trono de España el Príncipe que ostentando la legitimidad de origen, posea también la de ejercicio, siguiéndose en todo caso la tradicional ley sucesoria de la gloriosa Monarquía Española. El Jefe del Estado o en su defecto el Consejo del Reino, señalará la persona en quien recaiga el mejor derecho...» ${ }^{28}$.

La Ponencia, en cambio, aceptó «en espiritu» las recomendaciones de los señores de Cura y del Río en relación a eliminar la frase «mejor derecho", para ampliar las facultades a la hora de elegir la persona de sangre real que mejor pudiese servir los destinos de la Patria.

Pero, el tema más grave del proyecto $-\mathrm{y}$ como hemos dicho antes sugirió el mayor número de enmiendas- fue el de las posteriores sucesiones, por cuanto los mecanismos sucesorios para todo un futuro indefinido en la Jefatura del Estado se pretendían regular con esta Ley. Para Serrano Súñer no se podían conjugar los dos objetivos que a tenor del proyecto se deducian del mismo: regular la sucesión del Caudillaje por la Monarquía, condicionando en aspectos fundamentales tal sucesión, a la vez que reglar "una constitución del régimen futuro". Ambos objetivos -a juicio de Serrano- no se pueden conjugar por cuanto «no parece que puedan, con buen método, ordenarse en un mismo cuerpo legal. $Y$ si se insiste en abarcar los dos objetivos será indispensable establecer entre ellos una clara distinción, separando la parte que se refiere a cuestiones de transitoria consideración y la que afecta a materias de permanente regulación; porque, no es posible, sin peligro de grave confusión, pretender que sea

27 Enmienda núm. 9.

28 Enmienda núm. 2. 
uno y el mismo el sistema sucesorio accidental para el tránsito del caudillaje a la monarquía -que no es un hecho político excepcional- y el sistema sucesorio normal para la monarquía ya restablecida ${ }^{29}$.

Previsor de los intentos, don Juan declaraba el 7 de abril de 1947 en Estoril que «en momentos tan críticos para la estabilidad política, no puedo dejar de dirigirme a vosotros, como legítimo representante que soy de vuestra Monarquía, para fijar mi actitud ante tan grave intento". Ante este ataque al principio hereditario, el pretendiente no podía sino atestiguar que «los principios que rigen la sucesión a la Corona y que son uno de los elementos básicos de la legalidad en que la Monarquía tradicional se asienta, no pueden ser modificados sin la actuación conjunta del rey y de la Nación legítimamente representada en Cortes. Lo que ahora se quiere hacer carece de ambos concursos esenciales pues ni el titular de la Corona interviene, ni puede decirse que encarne la voluntad de la nación el organismo que, con el nombre de Cortes, no pasa de ser mera creación gubernativa. La Ley de Sucesión que naciera en condiciones tales adolecería de un vicio sustancial de nulidad». Recalcaba a continuación que «la Monarquía hereditaria es, por su propia naturaleza, un elemento básico de estabilidad, merced a la permanencia institucional que triunfa de la caducidad de las personas y gracias a su fijeza y claridad de los principios sucesorios, que eliminan los motivos de discordia y hacen posible el choque de los apetitos y las banderías. Todas estas supremas ventajas desaparecen en el Proyecto sucesorio, que cambia la fijeza en imprecisión, que abre la puerta a todas las contiendas intestinas y que prescinde de la continuidad hereditaria para volver, con lamentable espíritu de regresión, a una de esas imperfectas fórmulas de Caudillaje electivo en que se debatieron trágicamente los pueblos en los albores de su vida política ${ }^{30}$

Resulta incuestionable que la Ley Fundamental vigente padece de confusiones y lagunas "capaces -a juicio de Pabón- de agravar las circunstancias de crisis políticas en las que tendría que aplicarse» puesto que «la Ley convierte la decisión sobre la persona en una elección del Régimen, que no se tramita como tal y que no es objeto de propuesta explícita. Además, la exigencia de quórum y la falta de determinación en el plazo favorecen de hecho la eliminación de la Monarquía ${ }^{31}$.

29 Enmienda núm. 9.

30 Manifiesto de don Juan, loc. cit.

31 Informes de Pabón a la Ley de Sucesión de López Rodó, La Laguna hacia la Monarquía. Noguer, 1977, págs. 545-549. 
De tal confusión y desconcierto se hicieron eco los Procuradores enmendantes. La enmienda de Ricardo Fernández Cuevas y Salorio -acompañada de la firma de Eduardo Ozores Arráiz- pretendia que se dijera claramente y de modo expreso que la pretensión del proyecto de Ley era únicamente establecer las normas para la sucesión del actual Jefe del Estado, «haciendo referencia, para posteriores sucesiones, a las Leyes que sean adecuadas». «Si la Ley pretendiera regular las posteriores sucesiones, no conduciría al establecimiento de nuestra Monarquía Tradicional, sino a un régimen de Monarquía electiva, demasiado tradicional (de hace trece siglos), y demasiado peligrosa». Pero, a juicio de Fernández Cuevas había algo más importante y grave pues, "el llamado a ser rey... si tiene conciencia de su propia dignidad... no podrá renunciar a los derechos de sus hijos. Este supuesto erróneo hacía que la Ley impidiese lo que pretende; ya que, o nunca habría rey o nunca, el que reinare, sería digno de serlo... Si el proyecto de Ley se refiere a la sucesión indefinida en la Jefatura del Estado, el régimen así constituido se apartaría de nuestra Monarquía histórica, al prescindir del principio tan esencial como es el de la sucesión hereditaria, que es una de la mayores -si no la mayor-entre las ventajas del sistema. Si se estima que la Monarquía conviene a España será precisamente, por sus principios fundamentales y no por los elementos accesorios; y poca prudencia sería desvirtuarla, justamente en lo que se considera como una de las mejores características del modo de ser de los españoles». Por todo ello, pretendían la inclusión de un posible artículo noveno en el que se señalase que todo cuanto en la presente Ley se refiera a la sucesión de la Jefatura del Estado, afectase única y exclusivamente a la de quien, a título de regente, le hubiese sucedido. Así, «La sucesión de quien, con título de rey, ostente la Jefatura del Estado español, se regirá por las normas establecidas en los artículos 77,78 y 80 de la Constitución de 1869»32. La Ponencia aceptó, pero con mayores limitaciones, el establecimiento de un orden sucesorio a partir de la instauración de la Monarquía.

El procurador Emilio Laguna, tras afirmar su conformidad con los dos primeros artículos del Proyecto observaba, en cambio, en los restantes artículos y en el espíritu del mismo de la disposición no se hallaba suficientemente claro el que la persona que ejerza la Jefatura del Estado marcase ya por sucesión el Derecho hereditario a la Corona, en sucesivas vacantes, entendiendo el firmante fundamental el concepto hereditario en la Corona, ya que de no ser asi «se llegaría a la existencia de una Monarquía electiva que, a juicio del escribiente, tiene todas las desventajas de la

32 Enmienda núm. 12. 
República... y aterra pensar la repetición de actos de carácter público que sobrevendrían si se utilizara la elección cada vez que quedara vacante la jefatura de la nación para sucesivas renovaciones». Por ello, creía oportuno suprimir el párrafo segundo del artículo $3^{\circ}$ por estimar que existian personas de realeza de sangre "con perfecto derecho a ocupar en el momento que se se juzgue necesario o conveniente la Corona de España» ${ }^{33}$. A juicio de Buenaventura Benito Quintero «establecida la Monarquía, elegido el Monarca, se considerará como norma reglada de sucesión el artículo 60 de la Constitución Española de $1876^{34}$, propuesta que también recogia en su enmienda Sabino Alvarez Gendín, para quien el régimen de Monarquía electiva no gozaba de las ventajas de continuidad y serenidad de las Monarquías desempeñadas por monarcas que «no han alcanzado la estulticia, la versatilidad o la incapacidad física». La mayor parte de las enmiendas referidas, la Ponencia las aceptó en espíritu, aunque con limitaciones considerables, puesto que no podía aceptar que la Ley hereditaria tradicional de la Monarquía Española fuese exclusivamente la contenida en las Partidas. A pesar de ello en el debate de la Comisión varios Procuradores reincidirian sobre este punto, de tal modo que Manuel Valdés invocaba la Ley hereditaria tradicional de la Monarquía «fundamentada en las leyes de las Partidas y recogida sin excepción en todos nuestros textos constitucionales, como el artículo 177 de la Constitución de 1812, el artículo 51 de la 1837, el artículo 50 de la de 1845, el artículo 56 de la de $1856 \ldots$... En todas estas etapas históricas... se ha venido claramente transcribiendo en todos los órdenes sucesorios como ley fundamental los textos contenidos en las Leyes de las Partidas»35. Por su parte, Antonio Goicoechea señalaba que todos estaban conformes con un principio, cual era que «lo que se instaura, una vez establecido el rey en el Trono, es una Monarquía hereditaria, y no electiva", si bien fue contestado por José Félix de Lequerica en términos tajantes. "No, es una Monarquia, en cierto modo electiva, puesto que sigue en pie lo que dice otro articulo establecido que, si a juicio de los reunidos no existiera persona de la estirpe que posea dichas condiciones, o la propuesta no hubiese sido aceptada por las Cortes, propondrán como regente a la persona que por su prestigio, capacidad y méritos deba ocupar este cargo» ${ }^{36}$.

Don Esteban Bilbao en el Pleno de las Cortes del 7 de junio pretendió que el principio hereditario, tan ardorosamente criticado desde diversas alas, había estado a salvo siempre en el proyecto de Ley de Sucesión, al

33 Enmienda núm. 8.

34 Enmienda núm. 16.

35 Actas de la sesión del dia 30, $1^{\text {er }}$ turno, cc. 6 y 7.

36 Actas de la sesión del dia 31, $1^{\text {er }}$ turno, cc. 6 y 7. 
que calificaba como «la más perfecta adecuación posible entre la idea y la realidad, dentro de los imperativos de un Orden social cristiano». Para salir al paso de aquellos que argüían diciendo que «nuestro proyecto, exagerando sus previsiones, compromete esencialmente el principio de las Monarquías hereditarias», sentenció que «el principio de la herencia está salvado reiteradamente en nuestro proyecto. Ya lo estaba en el primitivo, donde se llamaba a suceder al príncipe de sangre real y de mejor derecho. Lo está en nuestro proyecto, donde el Jefe del Estado, el rey en su caso, puede designar, claro que de acuerdo con las Cortes, al sucesor que tenga las condiciones preceptuadas por la Ley... La transmisión del derecho a persona distinta, aunque de la estirpe, es un evento excepcional, pero que debe preverse y más excepcional el caso de que entre los príncipes de la sangre, dadas las circunstancias de la Nación y sus circunstancias personales, no haya alguno que reúna las condiciones necesarias para el ejercicio de la realeza ${ }^{37}$. Carecen de razón los que afirman -continuaba Esteban Bilbao- que tratamos de resucitar con sus anacronismos y peligros el régimen de las Monarquías electivas; lo que tratamos de salvar es el carácter social de la institución y la institución misma en el trance, siempre difícil, en que una aplicación rigurosa de la ley de herencia pudiera comprometer los sagrados intereses de la Patria». A la luz de este último párrafo no cabia, pues, sentencia tan tajante como la anterior.

No congeniaban tales afirmaciones con el contenido de varias enmiendas, como la de Serrano Súñer, para quien el proyecto -como ya hemos visto- desvirtuaba la esencia de la Monarquía Tradicional pues «a las condiciones de mejor derecho y otras que se consignan se agregan las de conveniencia, prestigio y posibles asistencias de la Nación». Su posición la clarificaba seguidamente pues «sígase un sistema u otro -la Monarquía electiva o el principio hereditario-, manténgase el de hoy o restáurese el de ayer, pero no cerremos, unos y otros, el que, en definitiva, es el único camino de la España rescatada con la irrevocable victoria militar de abril del 39... Si la Monarquia es el único camino, no lo cerremos con mixtificaciones, porque si se hace así (lo que fatalmente ocurrirá, contra la mejor intención que en todos presumimos, si el proyecto se convierte en Ley), nos habremos creado una situación que, lejos de resolver nada, será la misma que tenemos ahora planteada, sólo que, además, con todas las naves quemadas" ${ }^{38}$.

El proyecto, además de este ataque, más o menos velado a la institución monárquica, se diferenciaba de los textos constitucionales monárqui-

37 BOC, pág. 4022.

38 Enmienda núm. 9. 
cos en otros aspectos. El artículo $9^{\circ}$ del dictamen de la Comisión establecía entre los requisitos para ejercer la jefatura del Estado el ser varón y haber cumplido la edad de treinta años. Varias enmiendas anteriormente habian prestado su atención a este punto último. Para Álvarez Gendín «al llegar el Infante con más derecho a la edad de 16 años, deberá ser jurado por las Cortes", mientras Buenaventura Benito Quintero la incrementaba en dos años. Más tajante era Serrano Súñer por cuanto no estaba justificada la exigencia de 30 años para ejercer el oficio de rey, "que carece de apoyo en la Historia, en el Derecho Público y en el Derecho Civil», proponiendo la edad de 21 años. Respecto a la condición primera -el ser varóntanto Serrano Súñer como Alvarez Gendín, para quienes no había razones demasiado sólidas para su exclusión, intentaron enmendar el proyecto. La Ponencia no admitió tales sugerencias, sentenciando que «aunque transmitan sus posibles derechos a los herederos, no deben ejercer la Jefatura del Estado". Redundando en ello, Esteban Bilbao concluía que «la condición precisa impuesta por la necesidad de los tiempos en los que, si no hay reinos peninsulares que fundir, rige la necesidad de los poderes fuertes, incólumes a la complicación de influencias extrañas, donde, abusando del poder marital, peligraría fácilmente la paz del matrimonio - la paz de los pueblos, comprometidos acaso, si no por los celos de una pobre reina loca de amores, sí por la pasión de un extranjero enamorado de su antigua Patria»39.

Abundando en otro aspecto de la Ley de Sucesión, el artículo $1^{\circ}-\mathrm{al}$ que ya nos hemos referido- declaraba que «España, como unidad política, es un Estado católico, social y representativo", si bien en el Proyecto de Ley únicamente se le calificaba como católico y social. Fue esta definición del Estado español una de las materias más conflictivas. Señalemos al respecto varias enmiendas tendentes a perfilar el significado del artículo. Serrano Súñer pretendía soslayar el término «social» pues «todo Estado, lo quiera o no, es «social» en el sentido opuesto a «individual», tanto que lo social es un supuestó inexcusable, una condición sine qua non de lo político". En la misma línea Fernández Cuevas concluía que "verdaderamente esto es no decir nada, pues malo puede ser un Estado que no sea social». Más sorprendentes, sin embargo, eran dos afirmaciones del mismo procurador. En primer lugar, desechaba la expresión "católico» por cuanto "Un Estado, aunque sea el Español, no es, no puede ser religioso; el Estado es un ente abstracto, que no puede recibir los sacramentos, que no es susceptible de salvarse o condenarse en sentido religioso... El Estado no puede ni serlo ni no serlo (católico)». Y añadia: «lo que en el artículo $1^{\circ}$ se quiere decir es que se ajustará a las normas de la moral católica.

${ }^{39}$ BOC, pág. 4023 
Pero aún así la palabra católica no parece la más adecuada, pues se le atribuye... un contenido más especificamente religioso que a la palabra cristiana; y lo que, sin duda alguna, se pretende es que el Estado Español se atenga a las normas de la moral cristiana». La Ponencia, por la misma razón, desestimó las enmiendas de los dos anteriores, por cuanto los conceptos «social» y «católico» estaban perfectamente claros. Pero, conviene resaltar la enmienda de Fernández Cuevas por cuanto puede sernos un ejemplo de la visión simplificadora e idealista de determinadas materias políticas. De esta guisa, una de las consecuencias de atenerse a la moral cristiana por parte del Estado era la "verdadera democracia", que se contemplaba tanto en la vida civil como social. Pero, lo era también «por costumbre y temperamento; por su actual concepción del Estado como servicio para el Pueblo...; lo es en el propósito y espiritu de todos los españoles». Esto lo refería en cuanto a la democracia como ideología, mas al considerar la democracia como sistema de gobierno, «muchos dirán que nuestras instituciones no se ajustan a normas democráticas. $\mathrm{A}$ ello puede objetarse que muchas de ellas evolucionarán en ese sentido; pero, además, hay que tener muy presente que cada cual tiene su criterio propio sobre cuáles son las normas que distinguen un sistema como democrático y que bien podemos permitirnos el lujo de tener el nuestro". Concluia Fernández Cuevas que «deberá, pues, incluirse el concepto de democracia en la definición de nuestro Estado, primero porque es verdad y segundo porque pudiera ser más conveniente por razones obvias " ${ }^{40}$. Huelga decir que la enmienda fue rechazada por la Ponencia. No así la de Antonio Goicoechea, quien reclamó el calificativo de «representativo" para el Estado, "por estar de acorde con el informe de la Ponencia”.

Varios aspectos más destacan del análisis de la Ley de Sucesión. En primer lugar, ésta instituía Las leyes fundamentales de la Nación que, según el artículo $5^{\circ}$ del proyecto de Ley (décimo en su definitiva redacción por la Comisión) eran las siguientes: el Fuero de los Españoles, el Fuero del Trabajo, la Ley constitutiva de Cortes, la Ley del Referéndum Nacional y la presente Ley de Sucesión. Por ser éstas las Leyes cuyo juramento era condición sine qua non para ejercer la Jefatura del Estado, resulta obligado dedicarle unas líneas.

La expresión Ley fundamental aparece en el Reglamento provisional de las Cortes de 1943 al instituir una "Comisión de Leyes Fundamentales". La constitución vuelve a aparecer de nuevo en la Ley de 17 de julio de 1945, que aprobaba con carácter de Ley Fundamental el Fuero de los

40 Enmienda núm. 12. 
Españoles. Finalmente, el proyecto de Ley de Sucesión completaba y consolidaba las Leyes Fundamentales de la Nación.

Los Procuradores prestaron atención a este respecto y las enmiendas abundaron en apreciaciones. De ellas, dos tuvieron efecto en el informe de la Ponencia, por lo que, además de las ya referidas, sería Ley fundamental «cualquier otra que en lo sucesivo se promulgue confiriéndola tal rango". La primera de ellas tuvo como firmante a Vicente Galán pues creía «peligroso que una declaración exhaustiva cierre el paso a las que se reputan leyes fundamentales de un Estado que, como el nuestro, se encuentra aún en período constitutivo. Quizá baste hoy con las que se indican; pero, en un mañana más o menos próximo, tal vez sea necesario dar el rango de fundamental a leyes que hoy no están ni siquiera in mente». La misma intención albergaba la enmienda de Buenavetura Quintero ${ }^{41}$. Otras enmiendas pretendian la inclusión de otras Leyes que deberian paser a ser fundamentales. Manuel Valdés pretendía que se incluyera el Decreto de Unificación. Alberto García Ortiz incluía los 26 puntos de la FET y de las JONS. Estas dos últimas enmiendas encubrían una clara significación política ${ }^{42}$. Especial mención merece la enmienda de Rodríguez Jurado para quien faltaba una Ley fundamental cual era "el Fuero de la Justicia", que "constituye el común denominador -la justicia- de grandes masas de españoles que, con independencia de sus respectivas ideas políticas, nutren... el sentimiento popular de la justicia». Continuaba su enmienda denunciando la falta de fe en la Justicia y en el ejercicio del propio derecho: «inculcar ésta mediante preceptos de rango constitucional, llevar a unos y otros la creencia de que contra el posible abuso de poder de una autoridad gubernativa existe una autoridad judicial que le ampare; colocar al juez en la cúspide de las categorias sociales y dotarlo de medios e instrumentos jurídicos eficaces para hacer que todos, grandes y pequeños, respeten la Ley como base de la libertad; crear un verdadero poder judicial, independiente del ejecutivo... es tarea fundamental porque afecta a la constitución interna de España» ${ }^{43}$.

Este juramento de las Leyes Fundamentales se completó en el texto definitivo con la «lealtad a los principios que informan el Movimiento $\mathrm{Na}$ cional» a propuesta de los Procuradores Goicoechea y Galán. Se pretendía con ello garantizar la continuidad bajo la Monarquía instaurada del régimen nacido el 18 de julio de i936. Y asi se reconocía en el preámbulo del Proyecto que, si bien fue suprimido, es muestra de la intención política

\footnotetext{
41 Enmiendas $n^{\text {os }} 15$ y 16.

42 Enmienda $n^{\circ} 11$.

43 Enmienda $n^{\circ} 1$.
} 
que se abrigaba: «El respeto y la consideración debidos al pensamiento de los distintos sectores políticos que, integrando el Movimiento Nacional, se alzaron para la Victoria, y la experiencia de la vida política en el último siglo, han venido presidiendo hasta hoy la formación de las leyes constitutivas de nuestro Estado... Cualquier definición que se hiciera fuera del ideario general que a todos interesa, carecería de la asistencia general y la continuidad en el tiempo que materia tan importante demanda. Lo interesante para la nación es el contenido, el que no se desvirtúen los principios espirituales, patrióticos y sociales que el Movimiento alumbró, sin cerrarse el camino a que en cada coyuntura pueda regir los supremos destinos de la Patria, quien, fiel a aquellos principios, cuente con mayores garantias de acierto y con la asistencia y confianza de todos los españoles... Permanencia de las esencias del Movimiento, legitimidad de ejercicio, continuidad de la obra social y servicio a la voluntad de la Nación, esto es lo que persigue el presente proyecto.... ${ }^{44}$. Con idéntico espíritu manifestaba Esteban Bilbao en el Pleno de las Cortes que el nuevo monarca para serlo y poder ejercer debía ser «leal a la memoria de los caídos que con su sangre regaron los caminos de un trono cristiano asentado sobre el solar de la verdadera España», sentenciando: "desdichado consejo el de aquellos que, olvidando los deberes de la más evidente justicia, que en este caso van juntos con los deberes de la más obligada gratitud, pretendieran improvisar un Trono en escandaloso divorcio con el Movimiento que lo preparó y el Caudillo que lo proclama. Ninguna denuncia mayor como la de aquellos que quisieran instaurar un Trono condenando al ostracismo al Régimen y al Caudillo que acertó en la victoria y en la paz, restauró el orden y pacificó la Nación, para obtener el aprecio de quienes después de haber derrocado el Trono, saqueado el Erario Nacional y destrozado la Patria, impenitentes en su despecho, ya no puedan consumar sus planes siniestros, se contentarian por el momento con domesticar a su futura víctima". Por si cupiese alguna duda en las intenciones de los anteriores párrafos, el mismo Esteban Bilbao concluye: «Si la Monarquía ha de volver, ha de venir con Franco o no vendrá, con un sentido de continuidad, como una garantía del orden, como un atributo de nuestra inalienable victoria. La victoria del primero de abril, que no fue porque no podía ser, que no será porque no debe ser, un Convenio de Vergara sellado por la traición, sino el triunfo definitivo de una España rediviva, donde los vencedores puedan ostentar sus laureles, no para azotar con ellos la frente de los vencidos, no, pero sí para coronar con ellos las sienes augustas de la Patria» " «Por esta razón -continúa el Presidente de las Cortes- las Cortes

44 Preámbulo del proyecto de Ley en $B O C, n^{\circ} 194$, págs. 3911-3912.

45 BOC, pág. 4025. 
Españolas adoptan este proyecto de Ley que, en definitiva, no es otra cosa que la consagración de los ideales que inspiraron el Movimiento Nacional... España ya está unida y en orden; icontinúa la Historia de España!. Franco, pues, se convertía en el moldeador de la nueva Monarquía, en el «hacedor de reyes». La historia habría de encargarse de demostrar el verdadero talante liberal y democrático de la Monarquía que había de venir, que lejos de situarse entre los principios políticos se situaba sobre los mismos, desterrando los rencores y hermanando a todos los españoles. La continuidad que se pretendió rubricar en la institución monárquica se diluyó en el verdadero sentido social y cristiano de la Corona española, por ende democrática y representativa.

Uno de los aspectos más confusos y oscuros del Proyecto de Ley de Sucesión es el concerniente a la fórmula regencialista. De esta guisa, el artículo $7^{\circ}$ del proyecto confirmaba que en cualquier momento el Jefe del Estado podría proponer a las Cortes la designación de la persona llamada a sucederle, pero sin especificar si lo sería a título de rey o regente. La enmienda de Alvarez Valdés demandaba la designación de regene cuando la persona propuesta para ejercer la Jefatura del Estado no reuniese las condiciones o no hubiese sido aceptada por las Cortes, mientras que Vicente Galán proponía que la elección de regente fuese preceptiva de no elegirse rey "y que su mandato se circunscriba a un período de tiempo limitado, porque no consideramos conveniente que rechazada una propuesta de rey, vuelva a proponerse otro, y, cual el preámbulo afirma, «la coyuntura feliz que elevó a la superior dirección de los destinos de la Patria al Caudillo de la Cruzada... no es fácil que se repita", y creemos asimismo peligroso que vitaliciamente se designase regente a cualquier otro ${ }^{46}$. Se trataba, pues, de poner claridad y precisión en el precedente equívoco, de tal modo que la Ponencia lo aceptó y así pasó al artículo $6^{\circ}$ de la Ley esta apreciación disyuntiva. Mas, el texto definitivo todavía abundó en otras singularidades, puesto que a tenor del artículo $6^{\circ}$ el Jefe del Estado podía proponer rey o regente en su sucesión, pero sin sujetarse a ningún orden de prioridad, por lo cual "cabe suponer que el sucesor en este caso lo es en términos idénticos al sucedido" ${ }^{47}$, mientras cuando se trata del regente propuesto por el Gobierno y el Consejo del Reino (artícu$108^{\circ}$ ) se fijan plazos y condiciones («al formular resta propuesta podrán señalar plazo y condición a la duración de la Regencia, y las Cortes deberán resolver sobre cada uno de estos extremos»). Por esta primera vía -en palabras del propio Pabón- «el regente que sucede al actual Jefe del Esta-

46 Enmienda núm. 15.

47 “informe de Pabón", en Gil RoBles, op. cit. 
do, aplicando el artículo $6^{\circ}$, puede proponer y obtener la designación de otro regente. Este podrá hacer lo mismo. $Y$ una cadena de regentes cerrará el paso al rey ${ }^{48}$. Pabón remataba su crítica a la solución regencialista afirmando que «la mudanza del rey al regente... parece oponer dos figuras, no sólo compatibles sino interdependientes. El regente supuso siempre el Reino y actuó históricamente en nombre del rey. Lo normal no fue la alternativa, sino la coexistencia del regente y el rey, en tanto el segundo no sube al trono o no ejerce la realeza. En la Ley de Sucesión no se considera la normal y simultánea designación del rey y del regente» ${ }^{49}$.

A Pabón no le faltaba razón, pues una atenta lectura de los textos constitucionales del siglo pasado nos descubren precisamente el verdadero carácter de la Regencia, limitando su ejercicio hasta la mayoría del rey y a los parientes más próximos al monarca. Conocedor de la tradición, Manuel Valdés relata su punto de vista en la Comisión Especial:

\footnotetext{
« ¿Cuánto ha de durar esta Regencia? Si la Regencia -y conste que me refiero al caso de muerte del Caudillo- fuera nombrada por haber sido rechazada la persona de sangre real por las Cortes, entiendo que debe durar justamente, exactamente, hasta que esta persona de sangre real haya abdicado en su inmediato sucesor, el cual para efectos de nombramiento y proclamación se encontrará en idénticas circunstancias que su ascendiente, es decir, de haber sido nombrado por el Consejo de Regencia y propuesto a las Cortes y votado por los dos tercios de Procuradores...

Otro de los aspectos de mi enmienda prevé el caso de minoría de edad del príncipe de sangre real y en este caso la Regencia debe durar justamente hasta el momento de la mayoria de edad del príncipe de sangre real que por el Consejo de Regencia haya sido declarado con mejor derecho ${ }^{50}$.
}

Quedaría inconcluso el presente análisis de la Ley de Sucesión si no hiciésemos referencia a los dos Consejos que se encumbraban como esenciales en la nueva configuración de la Monarquía.

Los redactores del proyecto prestaron bastante atención a la configuración del Consejo del Reino -recuerdo de parecidos organismos de la Monarquía tradicional-, que aparece reflejada en el artículo $2^{\circ}$, por el cual éste asistiría al Jefe del Estado en aquellos asuntos y resoluciones trascendentales de su exclusiva competencia, siendo presidido por el presidente de las Cortes y compuesto por los siguientes miembros: el

\footnotetext{
48 «Informe de Pabón», op. cit.

49 "Informe de Pabón", op. cit.

50 Actas Taquigráficas del día $30,1^{\text {er }}$ turno, cc. 8 y 9 .
} 
cardenal primado, o arzobispo más caracterizado en caso de vacante o imposibilidad del titular; el general jefe del Alto Estado Mayor, o, en su defecto, el más antiguo de los tres generales jefes de Estado Mayor de Tierra, Mar o Aire; el presidente del Consejo de Estado; el presidente del Tribunal Supremo de Justicia; el presidente del Instituto de España; un consejero elegido por votación entre los procuradores en Cortes pertenecientes a cada una de las representaciones siguientes: la sindical, la de Administración Local, la de los rectores de Universidad y la de los colegios profesionales, y dos consejeros designados por el Jefe del Estado entre los procuradores en Cortes de su nombramiento directo. Este artículo, sin embargo, fue enmendado por Vicente Galán, quien sugería se sustituyese el cardenal primado por el primado de España o el arzobispo más caracterizado, "porque sabido es que los cardenales para la aceptación de cargos públicos necesitan solicitar la autorización del Santo Padre; y ello podría dar lugar a demoras, que en el caso, serían posiblemente perjudiciales para el alto interés de la Nación". La Ponencia aceptó en lo fundamental esta reseña, como también que el capitán general del Ejército de Tierra, Mar o Aire más antiguo y por el mismo orden sea consejero. Galán proponía, además, que dos consejeros fuesen elegidos por y entre los procuradores sindicales, porque "entendemos que si la Ley institucional de las Cortes Españolas atribuye a la Organización Sindical hasta un tercio del total de procuradores en Cortes, y en las actuales, 150 aproximadamente es el número de los que representan a los Sindicatos, aparece evidente que organización de esta importancia deba figurar en el Consejo del Reino, no con un sólo representante... ni aún siquiera con dos, como mesuradamente sugerimos, sino con tres. Porque si los Sindicatos equivalen a un tercio del total de procuradores... lógico sería que un tercio de ellos (consejeros) saliese de la representación sindical en Cortes... Por otra parte, no parece razonable equiparar a efectos de su presencia en el Consejo del Reino a un núcleo integrado por un tercio del total de procuradores, con la representación propia de rectores de Universidades y de los Colegios profesionales... es evidente que su entidad representativa es de volumen notoriamente menor que la de los procuradores Sindicales" ${ }^{51}$. La Ponencia no aceptó que fueran dos los procuradores elegidos por la Representación Sindical, como tampoco que igual número eligieran los representantes de la Administración Local y provincial, como propugnaba Manuel Valdés.

Una enmienda genuina fue la presentada por Wenceslao González Oliveros, quien comenzaba advirtiendo en la institución del Consejo del Reino un organismo jurídico susceptible de cumplir funciones permanen-

51 Enmienda $\mathrm{n}^{\circ} \mathrm{9}$. 
tes y de mayor alcance que la importantisima y concreta, pero «intermitente y efimera" que en Proyecto de Ley se preconcibe, en la creencia que este organismo "clara revelación de la originalidad y fecunda inextintas de la mentalidad política genuinamente española" puede deparar a la Nación la primera y magnífica oportunidad de restablecimiento de su intervención presencial y directa en el Estado. Reconocía tal primacía porque «nadie me negará que, de haber existido desde 1923 un órgano directivo del país, análogo al del Consejo del Reino, o bien la sucesión de los gravísimos acontecimientos políticos de los cinco últimos lustros no hubiera seguido tan destructora trayectoria..., o bien la nocividad de sus efectos hubiera podido diferir o reducirse al menos...., ${ }^{52}$. Por todo ello sometia a la Ponencia la denominación de "Consejo del Reino» por "Consejo de España», «para distinguir -sin reparar- a la nación de cualquiera de sus regímenes estatales posibles», y la sustitución de la frase «España, como unidad política» por «España como comunidad política», indicaciones ambas que no fueron aceptadas por la Ponencia. La primera por «implicar aquél (el Consejo del Reino) una Institución de rancio abolengo en la vida de la Nación, que se acopla más a la definición de Reino que en proyecto se hace para el Estado Español». En cuanto a «comunidad política», tampoco es admisible porque unidad política "afirma el sentido unitario de la Nación», postulado esencial del Alzamiento Nacional.

En el seno de la Comisión Especial también hubo propuestas. Así, José Félix de Lequerica intuía que la representación del trabajo era escasa en «organismo de tanta importancia como el Consejo del Reino", estimando debía ser menos oligárquico y representativo de las alturas sociales españolas, dotándolo de algún mayor contenido popular. González Oliveros pretendía que El Consejo asistiera perpetuamente al Jefe del Estado. Sanz Orrio deseaba un aumento en la representación de los Ayuntamientos por cuanto «en el Consejo del Reino lo que ha de pesar es el deseo del pueblo, que no ha de interpretarse por fórmulas de tipo científico ni técnico; estos técnicos no pueden interpretar en momentos decisivos el verdadero anhelo de la Nación. Siempre será más sustancioso conocer lo que opinan los millones de españoles encuadrados en los Ayuntamientos y Sindicatos que lo que opinan ocho señores Rectores designados por estas instituciones cuya vida política y cuya tensión es nula. En cambio, a juicio del presidente de la Comisión, no se podría enjuiciar la representación del Consejo del Reino sino de una manera representativa, ya que «la Iglesia, con todo lo que significa la Iglesia en España, no tiene más que un solo representante; el Ejército, con todo lo que representa, no

52 Enmienda núm. 13. 
tiene más que el capitán general. El presidente del Consejo de Estado representa todo lo que significa la Justicia". No prima, pues, el sentido representativo, ni arqueológico -como lo denominó Lequerica-, sino orgánico.

La intención de los procuradores fue potencializar la referida institución, como comprobamos en el debate en la Comisión del artículo $13^{\circ}$ en el que González Oliveros entendia que el dejar la iniciativa a la Corona del Jefe del Estado en asunto tan grave era contribuir a aislarla demasiado, por ello proponía que fuesen el Jefe del Estado y el Consejo del Reino los que informasen y propusiesen a las Cortes las personas excluidas de la sucesión. Esta iniciativa contrastaba con la opinión del señor Goicoechea, miembro de la Ponencia, para quien «el Consejo del Reino, por respetable que a todos nos parezca, no puede ser más que un organismo consultivon.

Respecto al otro Consejo -el Consejo de Regencia-, éste pasaba a convertirse en un organismo destinado a facilitar los mecanismos de la sucesión en el supuesto de que el Jefe del Estado falleciese sin haber designado sucesor. Según el texto del Proyecto, estaria constituido por el presidente de las Cortes, el cardenal primado y el capitán general del Ejército de Tierra, Mar o Aire, o teniente general en activo más antiguo, por el mismo orden (artículo $6^{\circ}$ del proyecto). El texto definitivo sólo tuvo una mudificación: la sustitución del cardenal primado por el prelado consejero del Reino de mayor jerarquía, por la misma motivación que se daba en el Consejo del Reino. Téngase en cuenta, pues, que este Consejo de Regencia está constituido por los tres sectores fundamentales en estos momentos de la Nación, como son la Iglesia, el Ejército y la Justicia, resultando para Manuel Valdés «el mejor Tribunal por entender sobre cuestiones de Derecho".

Este ha sido el paso del proyecto de Ley de Sucesión en la Jefatura del Estado por la Comisión Especial y, por ende, por las Cortes. En él se reflejan los tímidos intentos de modificación por parte de algunos procuradores en el sentido de darle una orientación más acorde con su mentalidad política. Pero, en puridad, ¿hubo verdadera oposición al Proyecto de Ley? Desde luego, no en las enmiendas estudiadas, como tampoco en el debate en la Comisión. Sin embargo, como ya hemos adelantado en páginas anteriores, José Luis Arrese, miembro de la Provincia, no firmó el informe de la misma, por no comulgar con el Proyecto. De hecho, unas anotaciones a la Ley de Sucesión que envió a la Ponencia, aunque «sin pretensión de voto particular», el día 28 de mayo de 1947, fueron omitidas por la censura. Sin duda alguna, manifestaba el malestar de la Falange 
ante tan grave agravio a sus principios ${ }^{53}$. Sin duda, Franco, con esta Ley de Sucesión se inclinaba lenta pero sistemáticamente hacia una solución monárquica de la todavía lejana pero insoslayable cuestión de preparar la era posfranquista. $Y$ esto estaba en contradicción con la doctrina antimonárquica de José Antonio Primo de Rivera, que los falangistas decían defender. Tanto es así que podemos considerar la Ley de Sucesión, junto con la firma de los «Pactos de Madrid» con los Estados Unidos en 1953, la Ley de Principios Fundamentales del Movimiento, entre 1956 y 1958, y el proceso de elección del sucesor de Franco, entre 1966 y 1969, como uno de los cuatro grandes mazazos del Régimen al falangismo, pero, a la vez, estas cuatro circunstancias pusieron de manifiesto con especial claridad la predisposición de los falangistas a aceptar todo cuanto propusiera el Caudillo, único medio posible de asegurar su propia supervivencia política. No obstante, de la mano de Arrese surgió la reprobación del Proyecto. Arrese, en la creencia de que ces un principio político incuestionable que la importancia de toda Ley de Sucesión es tanto mayor cuanto menor sea la fe que se tenga en la voluntad del rey que viene a servir», señalaba que la trascendencia que había tenido la Ley en el pueblo se debía primordialmente al hecho incuestionable de que «el porvenir de España está basado en la vida de un hombre y no en la permanencia de un sistema», llegando a afirmar que "no hay Régimen» pues en materia constitucional nada se habia hecho o no lo suficiente para ver con tranquilidad el porvenir. Por eso, y no por otra cosa, para el dirigente falangista la opinión general había trasladado a la cuestión de sucesión un entusiasmo político que «estaba llamado a ser puesto al servicio de lo fundamental» ${ }^{54}$. Por ello -a juicio del dirigente falangista- el proyecto no tenía razón de ser pues "no se limita, pese a su definición, a prever un cambio de personas en la primera magistratura del Estado; si la Ley se redujera a esto, a la forma de encontrar un sucesor capaz de continuar y completar la obra iniciada, no tendríamos nada que objetar a ella... Pero es que a la sombra de esto, el proyecto invade otro problema totalmente ajeno al propósito inicial, el de prejuzgar la forma de gobierno, lo cual es mucho más grave que hablar de sucesión en la persona del jefe». De este modo -pensaba Arrese-, lo que es sucesión en las personas se convierte en sucesión o modificación de formas de gobierno, "en algo que viene a dar otra forma al Régimen". No es extraño que el ponente llegase a la conclusión de la

53 José Luis ARRESE, «Anotaciones a la Ley de Sucesión» en Obras seleccionadas I: Treinta años de política. Ediciones Afrodisio Aguado. Madrid, 1966, págs. 1109-1115.

${ }^{54}$ Para Arrese, el complejo de normas e instituciones legales a que se daba el nombre de Régimen, «es actualmente sustituido en España por la persona del Caudillo. Gracias a su significación heroica y ejemplar en la Cruzada el Caudillo, durante diez años, ha hecho innecesario un Régimen para el vivir politico de facto del pueblo español... mas el régimen no existe", op. cit, pág. 1110. 
inutilidad de la Ley de Sucesión por cuanto que si no había Régimen no había nada que modificar, al no existir en modo alguno "esa imaginaria sustancia prima susceptible de recibir sobre sí una variedad de formas diferentes».

Estas consideraciones le impidieron firmar el dictamen de la Ponencia, exigiendo para hacerlo, que fuera separado del Proyecto cuanto se refiriese a la implantación de la forma de gobierno que en él se establecía.

Esta oposición falangista, junto a la oposición monárquica -aunque de distinto signo, y que ya hemos reflejado en páginas precedentes-constituyeron las dos únicas impugnaciones tajantes. Pero el Proyecto -como es sabido- siguió su curso normal y fue completada la Ley de Sucesión con las modificaciones que introducía la Ley Orgánica del Estado, en la que se puso fin al "tanto monta, monta tanto" en que se hallaban el rey y el regente, configurándose ahora la Regencia como un paréntesis «en tanto no se cumplan las condiciones del artículo 11 de la Ley", es decir, en tanto no se iniciara el orden regular de sucesión dinástica hereditaria. De este modo, la Monarquía pasa a ser la única desembocadura posible y definitiva de la Ley de Sucesión. Con la LOE además se introducen pequeñas modificaciones (se rebaja a los tres quintos el quórum exigido para la aceptación de la propuesta por las Cortes, juramento del heredero de la Corona, etc.), algunas de ellas de claro signo «monarquizante». 